\title{
دور اللغة العربية في عصر العولمة وتطبيقها في تطوير العلوم
}

\section{Dihyatun Masqon}

محاضر اللغة العربية والحضيارات الإسلامية بجامعة دار السلام كونتور

\section{Email : goodwords.dimas@gmail.com}

\section{Abstract}

This article aims to describe: 1) the role of Arabic language, 2) the interaction of Arabic with other living languages, 3) the linguistic growth methods possessed by the Arabic language, and 4) Some of the basics in teaching Arabic language for non-native speakers.

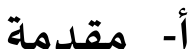

لقد كان حجر الأسـاس في هذا البناء الجديد للإنسـانية يتمثل في نظر الإسلام إلى الإنسان الذي يتبلور في الأمور الآتياة:

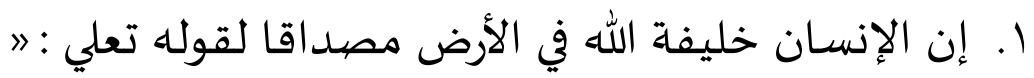
وإذ قال ربك للملائكة إني جاعل في الأرض خليفاةه.'

$$
\text { 'القرآن الكريم سورة البقرة، الآية: . r }
$$


r. إن الإنسان قد فضله الله تعلي على جميع الكائنات وكرمه أعظم تكريم، كما تعبر عن ذلك آيات القرآن

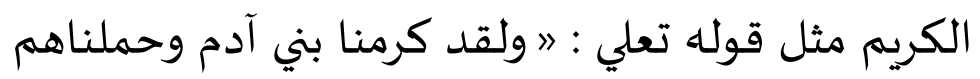

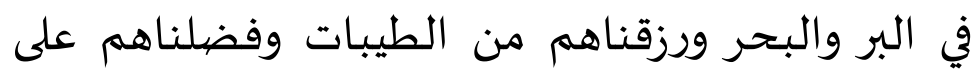
كثيرممن خلقنا تفضيلا《'

r. وبعد كل ذلك فقد زود الله تعالى الإنسان في رحلاته بالعقل الذي ميزه باه على سائر المخلوقات. وقد عبد الإنسان في رحاته

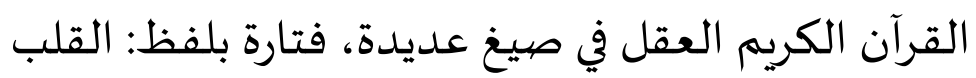

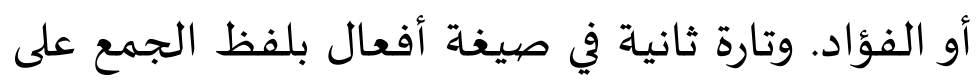
الأكثر مثل: يعقلون، ويفقهون، ويتفكرون، ويبصرون، وينظرون، ويعتبرون، ويتدبرون، ويعلمون، ويتذكرون.

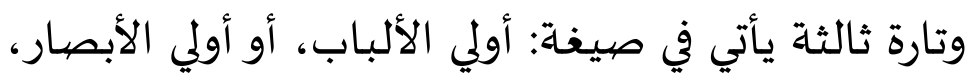

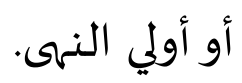

ومن الملاحظ أنه لا تأتي الإشارة إلى العقل في القرآن

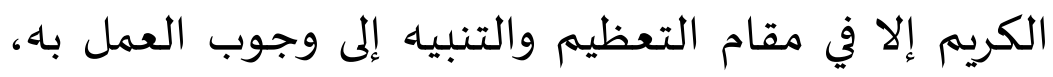
ومن هذا المنطوق يعتبر الإسلام عدم استعمال العقل خطيئة

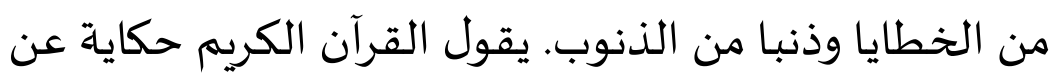

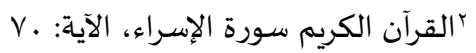


الكفار يوم القياماة: 》 وقالو لو كنا نسمع أو نعقل ما كنا في

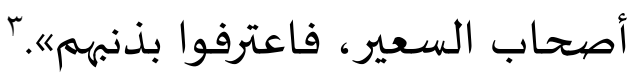

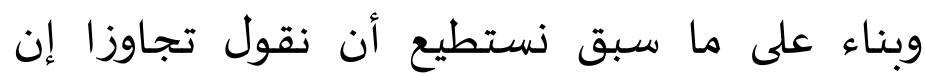
التفكير فريضبة دينية، ومناط إنسانية الإنسان وجوهرها.

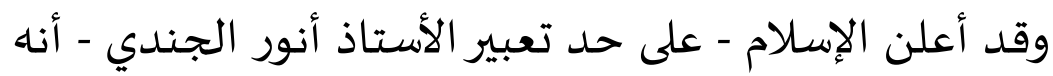

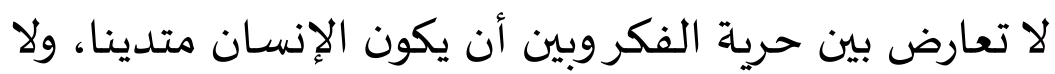

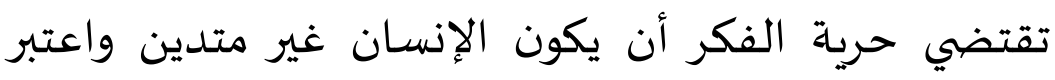
الإسلام أن أكبر تحرير للفكر هو تحريره من الوثنيات والمادة.

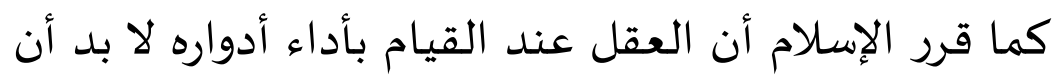

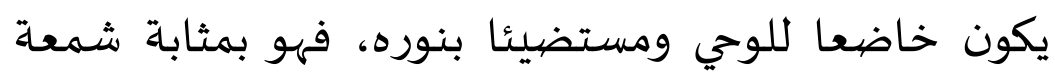

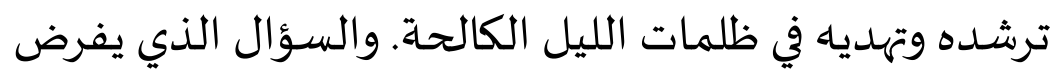
نفساه هو: ما هي القاعدة الرئيسية التي وضعها الإسلام في

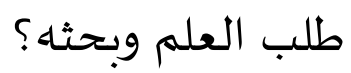
ب- القاعدة الأسـاسية في طلب العلم ولما كان مصدر العلم هو الله وحده القائل في محكم

$$
\text { " القرآن الكريم، سورة الملك، الآية: . 1-11.1 }
$$

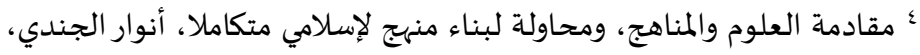

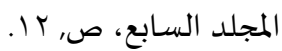

Jurnal Izdihār : Journal of Arabic Language Teaching, Linguistics, and Literature 
كتاباء: 》وفوق كل ذي علم عليم"، فقد أطلقت كلمة العلم

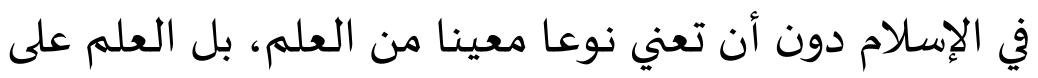

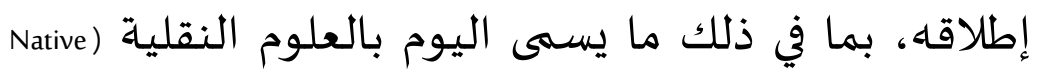

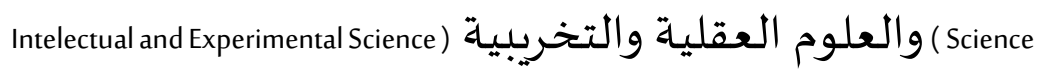
) والعلوم الإنسا نياة (Humanities).

وقد امتاز هذا العلم الإسلامي - إذا جاز لنا التعبير-

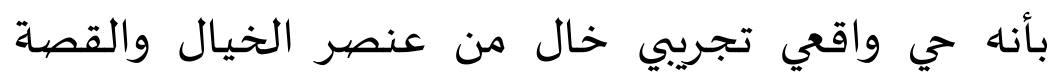
والتفسير الأسطوري، لأنه مقيد بالمالماحظة والاستقراء والتجربة. وقد أعلن الإسلام - كما ذكره صاحب سلسئ سلسلة

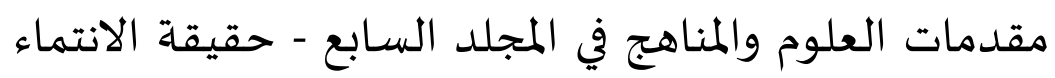

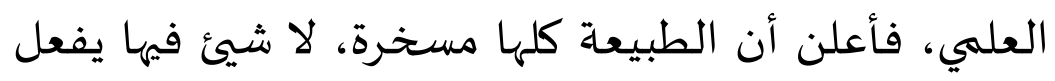

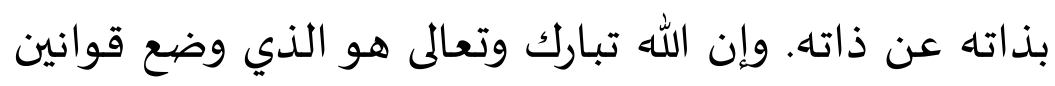

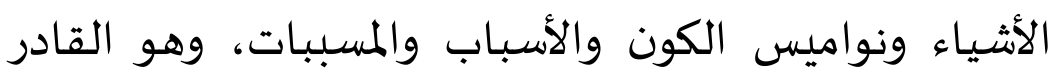

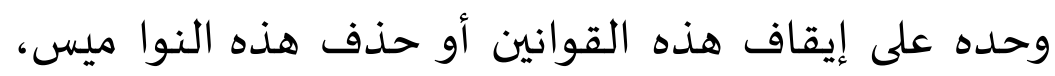

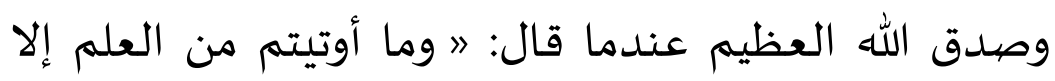
قليلا《.

وانطلاقا من ذلك المفهوم رسم الإسلام القاعدة

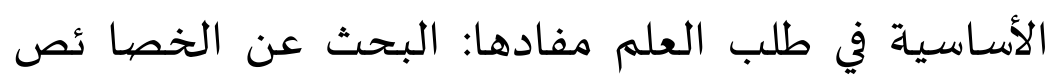

$$
\begin{aligned}
& \text { ×القرآن الكريم، سورة يوسف، الآية V7. } \\
& \text { جالقرآن الكريم، سورة الإسراء، الآية } 10 .
\end{aligned}
$$


وامتناع البحث عن الجوهر، `مصداقا لقول الرسول - صلى

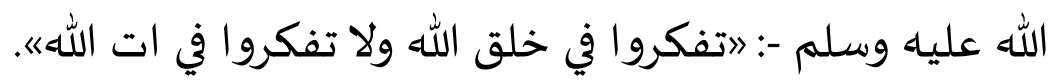
وعلى ضوء هذه القاعدة نرى سلفنا الصاح لم يشتغلوا أبدا

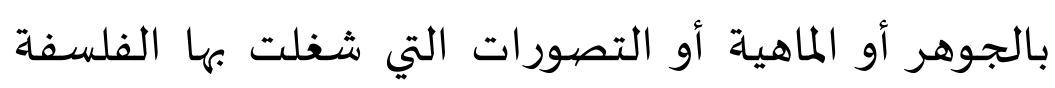

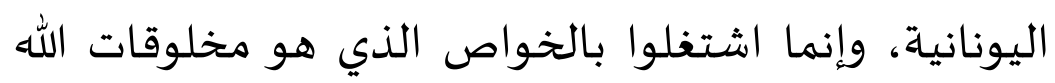

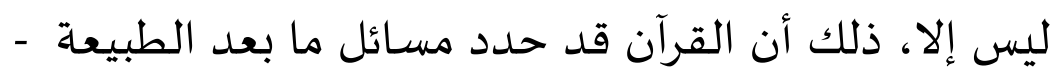

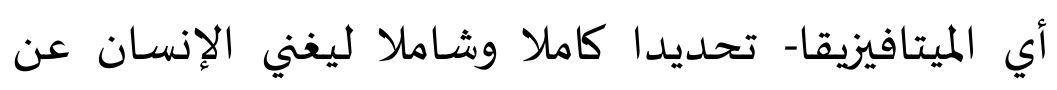

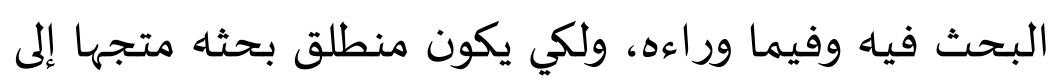

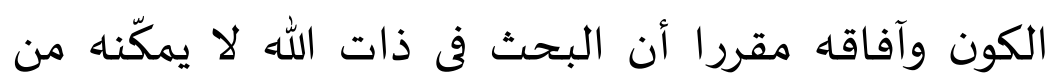

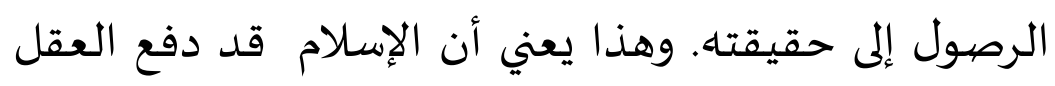

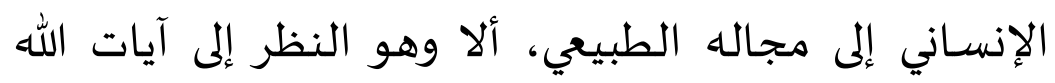

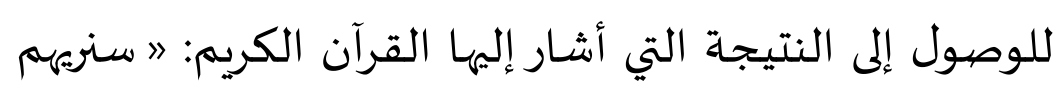

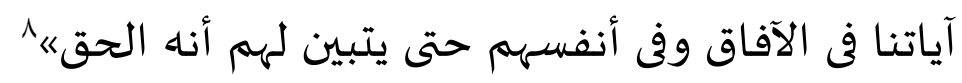

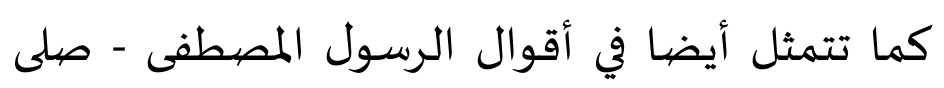
الله عليه وسلم -، منها: قوله: 》 طلب العلم فريضية على كل اقلى

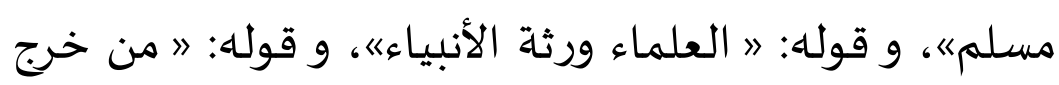

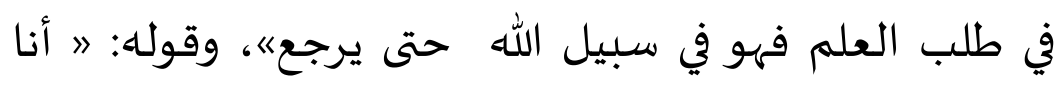

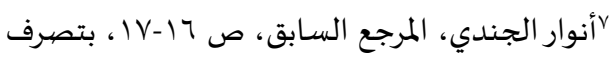

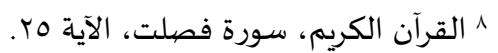

Jurnal Izdihār : Journal of Arabic Language Teaching, Linguistics, and Literature 
مدينة العلم وعلي بابها《، وقوله: 》الحكمة ضالة المؤمن، أين

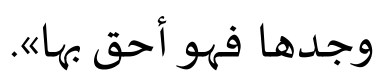

وكان من الطبيعي أن تصدر العلوم في الظهور،

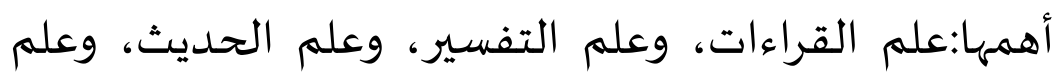

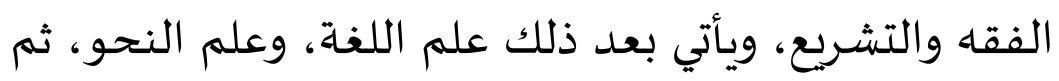
علم الكلام، وأصول الفقه. وبعد ذلك تأتي العلوم الإنسانية

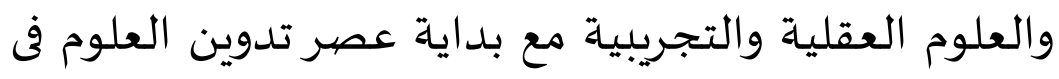
القرن الثاني الهجري أو الثامن الميلادي، ومن أهمها: علم بله

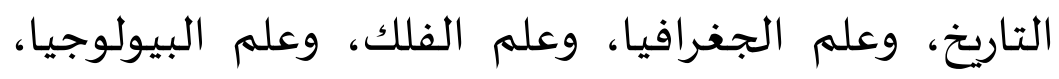
وعلم النفس، وعلم الرياضية، وعلم الفلسفة، وما زال الكشف يطول ويطول، مما جعل بعض الباحثين - منهم د.

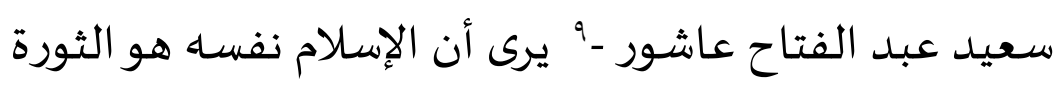

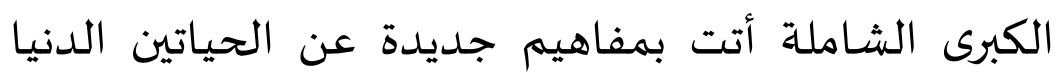
والآخرة.

الأمر الذي أقرته المستشرقة الألمانية د. سيغريد

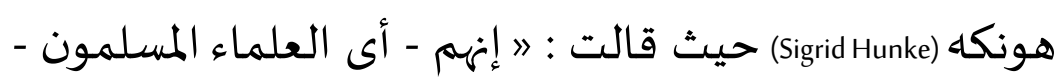

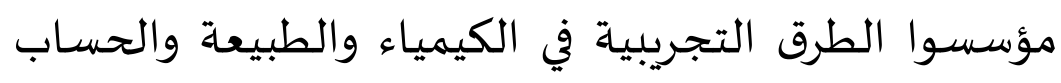

راجع: حضارة الإسلام، د. سعيد عبد الفتاح عاشور، معهد الدراسات 


\section{والجبر والجيولوجيا وحساب المثلثات وعلم الاجتاماع، وقد

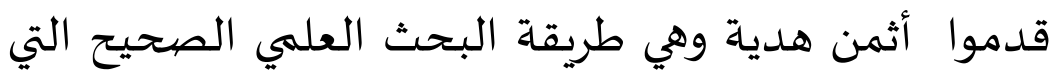

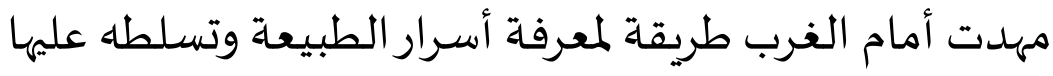

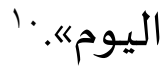

\section{وكان لكل علم وفن من هذه العلوم والفنون رجاله}

وعلماؤه ليس هنا مجال ذكرهم، وكل ما في الأمر ظلت تلك هن هده العلوم والفنون وستظل إنجازا رائعا للعقلية الإسلامية: دينية في الدوافع، لغوية في العرض والمادة، علمية في المنهج ومنطقية في التحليل والاستنتاج، الأمر الذي دفع الأستاذ دي الدهري بور (T.J. Deer) ليسجل إعجابه وهو يتحدث عن العلم النحو العربي قائلا:

Grammatical science, limited as it was to the Arabic language, retained its peculiarities upon which this is not the place to enter. At all events, it is an imposing production of the keenly observing and diligently collecting Arab intelligence, production of which the Arab might well be proud. ${ }^{11}$

· العيغريد هونكاه، شمس العرب تسطع على الغربي، أثر الحضبارة العربية في

أوربا، نقله عن الألمانية: فاروق بيضيون وكمال دسوقي، دار الجيل ودار الآفاق الجديدة،

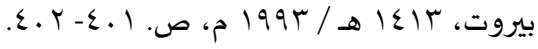

11 T.J. De Boer, The History of Philosophy in Islam, translated into English by Edward R. Jones, Cosmo Publication, New Delhi, 1983, p: 35.

Jurnal Izdihār : Journal of Arabic Language Teaching, Linguistics, and Literature 
برغم هذا كله احتفظ علم النحو بخصيائص له، ليس هذا مجال الإضافة فيها. وهو على كل حال أثر رائع من آثار

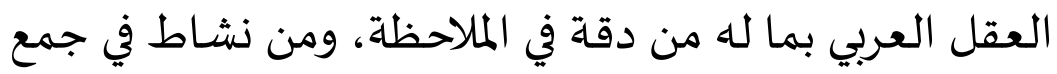
ما تفرق. ويحق للعرب أن يفتخروا باه).

ج- دور اللغة العربية

مما لايختلف فيه اثنان، كما شاهدنا من خلال العرض السابق، إن اللغة العبية ظلت ولا تزال لها شأن عظيم ومكانة سامية بين لغات العالم، فهي بالإضافة إلى كونها

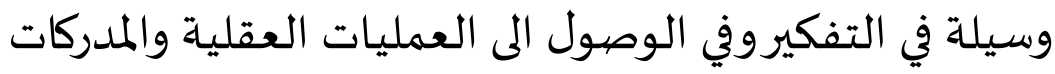

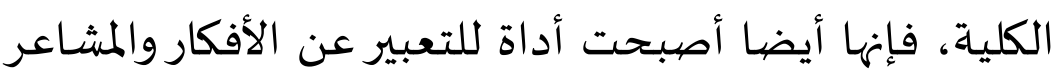
ولحفظ إنجازات الفكر الإنساني في مجال الثقافة والعلوم

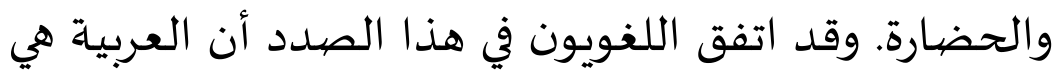

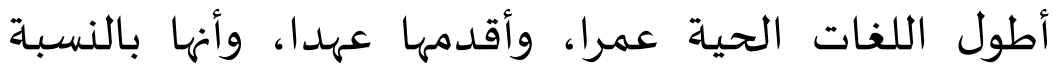

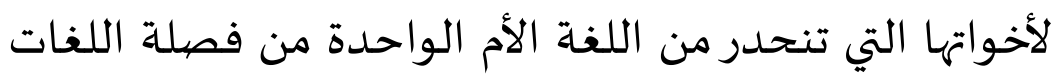

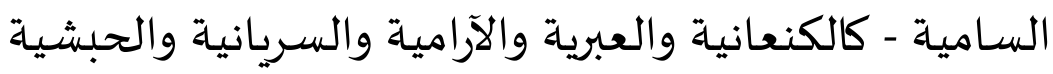

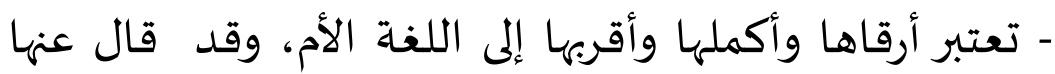
فيرجوسـون (Ferguson) : 
" Thus, in terms of number of speakers and extent of its influence, Arabic is by far the most important Semitic languages and must be regarded as one of important world languages 12

إن اللغة العربية اليوم سواء بالنسبـة الى عدد متحدلثيها أو الى مدى تأثيرها في غيرها من اللغات العالم فإنها تعدل من أعظم اللغات السـامياة وينبغى أن ينظر إليها على أنها إحلدى اللغات العظمى في العالم.

وهذه اللغنة العظيمة تتمتع بالخصيائص الممتيزة قلما توجدل في غيرها، وكل خصيصة منها تعد دافعا لنشرها وتعلمها، ولعل أبرز تلك الخصيائص هي ماياي:با إنها لغة اشتقاق تقوم على أبواب الفعل الثلاثي مما يسهل إيجاد صيخ جـديلدة من الجذور القديمة بحسب ما يحتاج إليه كل إنسان على نظام معين، ويترتب على ذلك وجود ثروة هائلة من المفردات حيث يمكن لها أن تزداد بلا

12 Ferguson, Arabic language, Enclopedia Britanica, vol: 2, 1971, p: 182.

rا للتفصيل راجع: أنور الجندي، مقدمات العلوم والمناهج، م: ع (اللغة والأدب

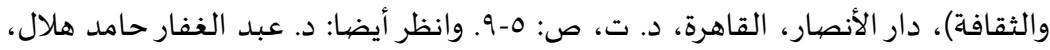

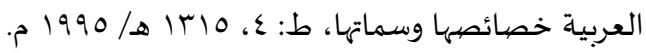


إنها تتميز بتنوع الأساليب والعبارات، فالمعنى الواحد يمكن أن يؤدي بتعبيرات مختلفة كالحقيقة والمجازوالتصريح

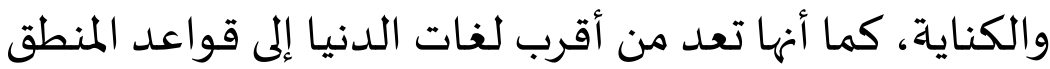
بحيث إن عبارتها سليمة طبيعية تهون على الناطق الصافي الهانيا

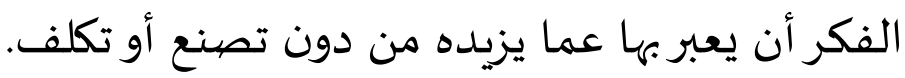

إنها لغة الفكر والثقافة والعقيدة، وهي لم تتراجع عن أرض دخلتها لتأثيرها الناشئ عن كونها لغة الدين ولغة الغنافه العلم والفكر من حيث هي لغة القرآن الكريم الذي القى إلى الفكر دونانيا الإنساني كله أضخم شحنـة من القيم والمبادئ.

ومن أبرز خصائصها أن ناطقيها اليوم، وبعد ألف وسبعمائة سنة يفهمون أشعار الجاهلية وحكمها وأمثالها

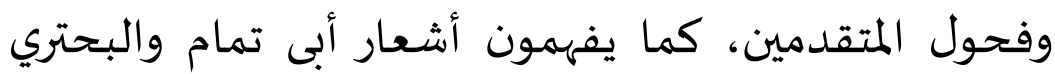

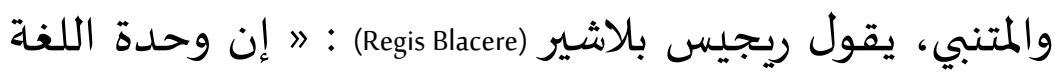

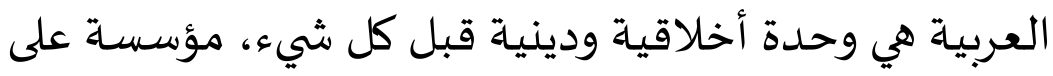
وحدة تاريخ اللغةها. وهذا يختلف عن حال اللغات وديليه الأوربية

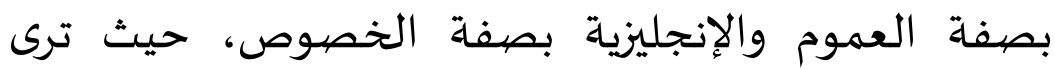
صباح غزاوي قائلة:

"Since classical Arabic has changed so little since Muhammad's time, Arab today can read Arabic written in seventh or eighth century without too much 
difficulty. This is quite different from the situation in English, as we cannot read old English texts without special study, as though for foreign language." 14

شاءت أقدار السماء أن يكون هناك التلازم بين اللغة العربية وبين الدين الإسلامي- وقد أكد هذا الوضع الواقع التاريخي - حيث أن الإسلام هو العامل الوحيد تدين له اللغة العربية، وإليه يرجع الفضل فى انتشارها وبقائها إلى أن يرث اللغة الأرض ومن عليها، فقد سارت فى ركاب الإسـلام أينما سـار وحلت حيثما حل. ولولاه لما كان لها شأن يذكر، إذ إنها فى ظلها أصبحت عاملا أساسيا لفهماه نظرا لارتباطها الوثيق بالقرآن الكريم، ذلك الكتاب الذي وصفاء الله جل وعلا بقوله : » الر. تلك آيات الكتاب المبين. إنا أنزلناه قرآنا عربيا لعلكم تعقلون《10 وقوله أيضا: " وإنه لتنزيل رب العالمين. نزل به إلمايه الروح الأمين. على قلبك لتكون من المنذرين. بلسان عربي مبينغ 17.

ثم إن اللغة العربية من الدين الإسلامي لا تنفصل عنه ولا ينفصل عنها وهى لا تدين للإسالام بانتشارها فحسب ولكنها

14 Sabah Ghazzawi, The Arabic Language, Washington DC, Center for Contemporary Arab Studies, 1992, p: 20.

$$
\begin{aligned}
& \text { 10 القرآن الكريم، سورة يوسف، الآية ا-Y. }
\end{aligned}
$$

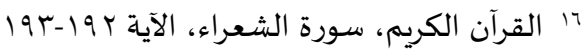

Jurnal Izdihār : Journal of Arabic Language Teaching, Linguistics, and Literature 
تدين لله كذلك بكل عواملها الأصلية التي نشأت أساسا لخدمة كتاب الإسلام.

\section{د- تفاعل اللفة العربية مع اللغات الحية الأخرى}

لم يكد يقترب القرن الأول الهجري من نهايته كانت

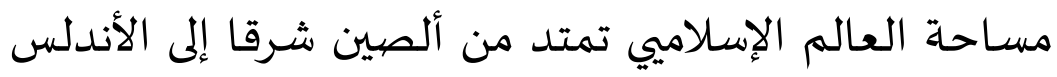

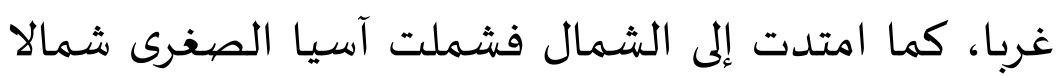

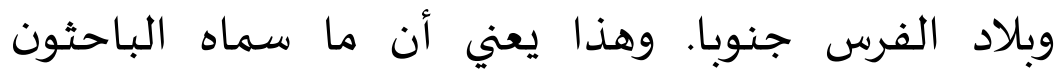
المحدثون بالعالم القديم قد وقع تحت سيطرة المسلمين الفاتحين ونفوذهم. وكان من لوازم ذلك أن يطلع المسلمون

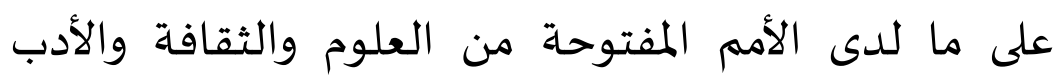

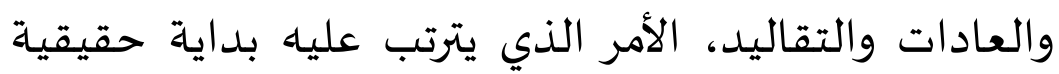

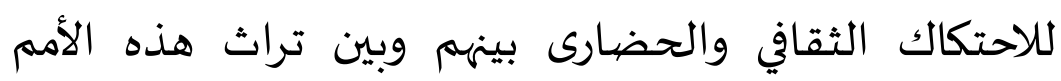
المفتوحة، وهو في جملته يتمثل في هذه الثقافات الثلاث، وهي: الفارسية، والهندية، واليونانية.

على أننا، في هذه المناسباة، أمام حقيقة ثابتة لابد من

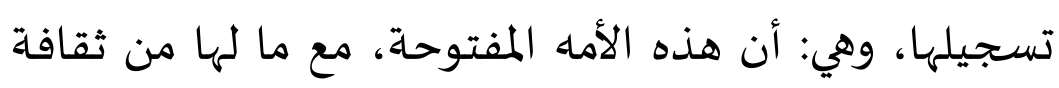

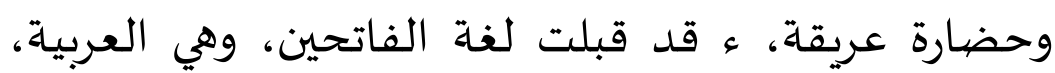


بصدر رحب وأياد مفتوحة، بل، وقد اتخذتها لغة للعلوم

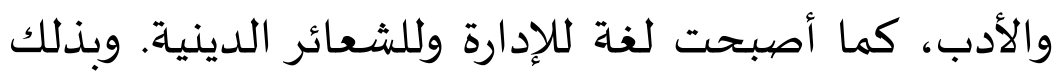
تحولت العربية في خلال قرن واحد فقط من لغة محلية إلى لغة عالمية. عن هذه الظاهرة الفريدة قالت المستشرقة ألمانية سيغريد هونكاه (Sigrid Hunke): 》وكيف يستطيع المره أهره أن يقاوم

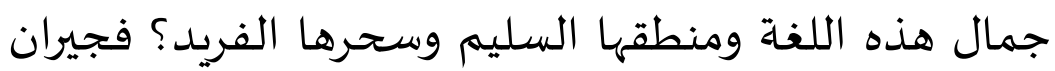

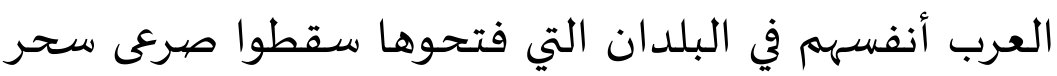

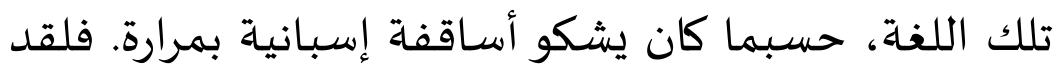
اندفع الناس الذين بقوا على دينهم في هذا التيار يتعلمون العربية بشغف، حتي إن اللغة القبطية، مثلا، ماتت تماما.

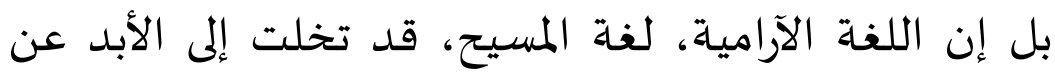

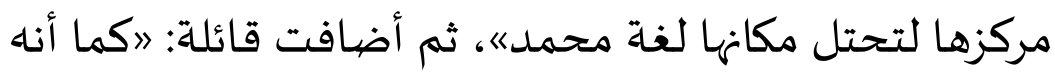

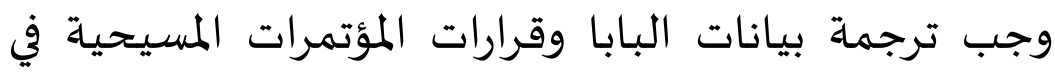

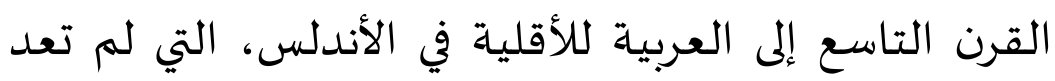

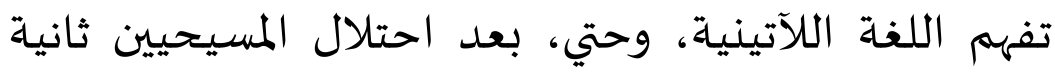

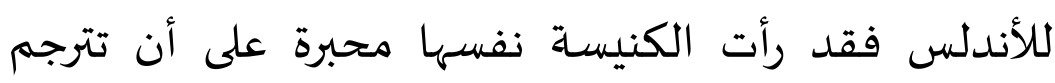

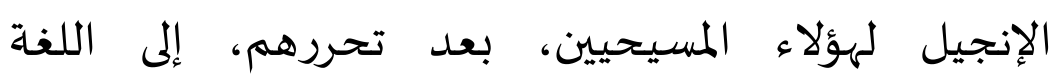

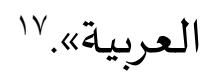

IV سيفريد هونكاء، المرجع السابق، ص: VTV.

Jurnal Izdihār : Journal of Arabic Language Teaching, Linguistics, and Literature 
قد ذكر د. علي عبد الواحد وافي وجود عوامل كثيرة ينشأ عنها ما يسهى بالصراع بين اللغات والتنازع على البقاء

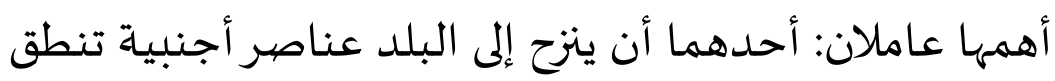

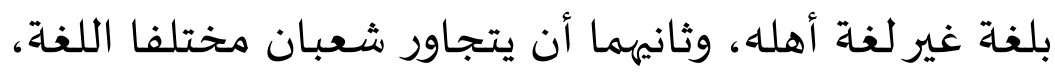

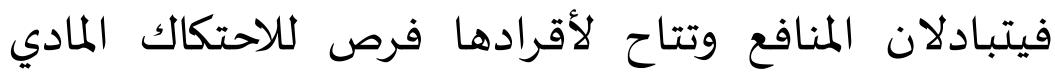

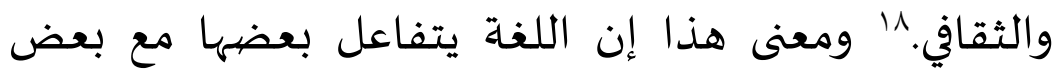

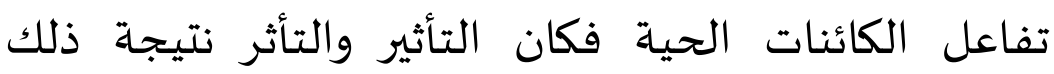
الاحتكاك المتواصل بينها. وهذا ما حصل بالفعل للغة العربية عند ما دخل الناس في دين الله أفواجا، وانضيمت إلى لواء الهاء

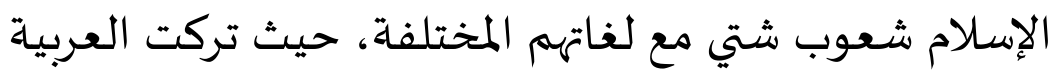
بصماتها الواضحة في اللغات الشرقية كالفارسية والأردية والإندونيسية، فلا يكاد يوجد سطر من سطور هذه اللغات ولا فقرة من فقراتها إلا وهو مزدحم بالكلمات العربية كما

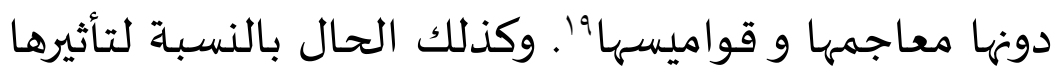

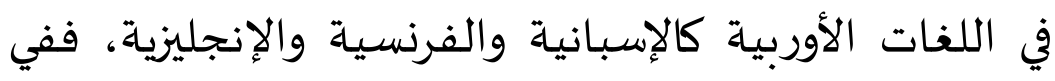

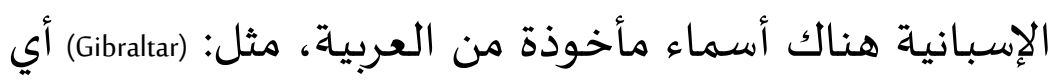

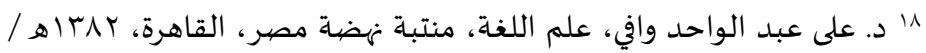

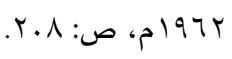

19 من الملاحظ جاء اثر العربية في هاء اللغات من ناحيتين، أولاهما في المعاملات

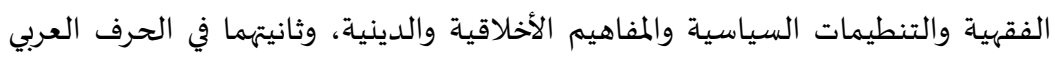
باعتباره أداة للكتابة فأصبحت تكتب بالحروف العربية. 
جبل طارق، وGuadalquivir) اي وادي الكبير، و(Averroes) أي ابن

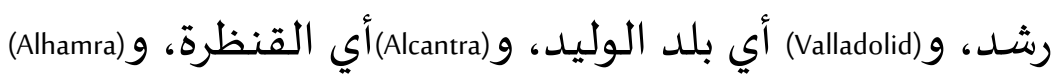

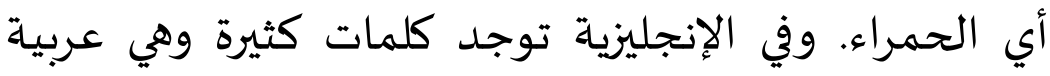

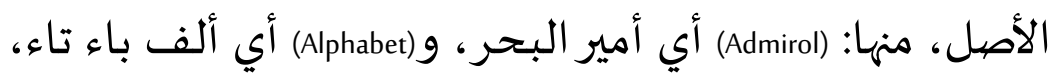

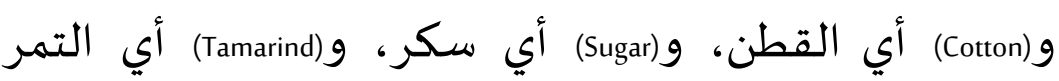

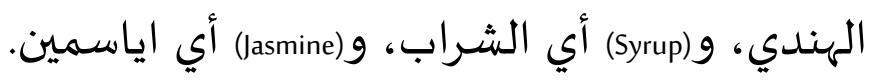

وأما تأثرها بغيرها من اللغات فمن الملاحظ أن

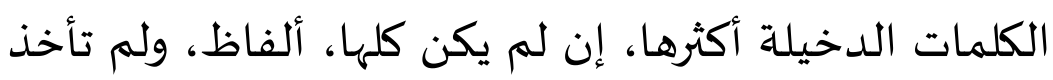

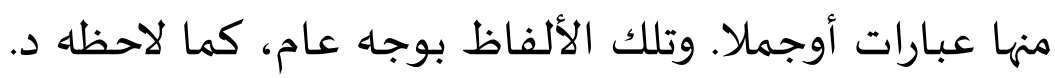

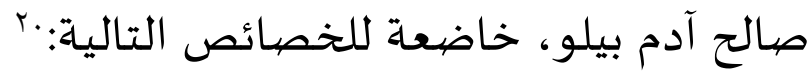

1. إنها قليلة القدر بالنسبة للكلمات الأصلية، وذلك أنها دخلت في العبية بعد أن تم لها كيانها، وأثبتت شخصيتها وصلاحيتها للتعبير عن جميع شئون الحياة ومتطلباتها، ولم تكن محتاجة للاقتباس من غيرها إلا في ألفاظ نادرة

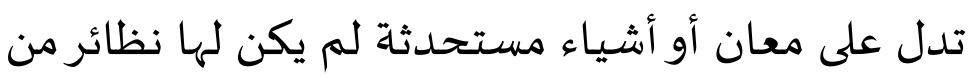

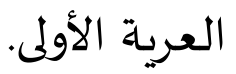

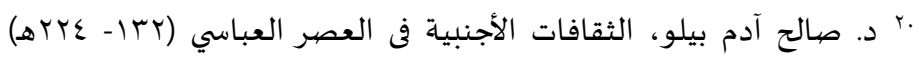

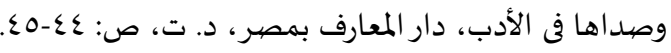

Jurnal Izdihār : Journal of Arabic Language Teaching, Linguistics, and Literature 
r. إن جميع ما أخذته العرية من غيرها كان أسماء، ولم

$$
\text { يكن حروفا أو أفعالا. }
$$

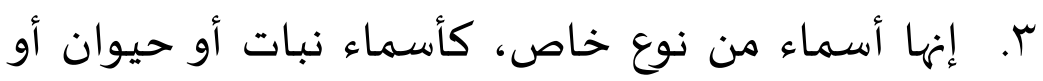

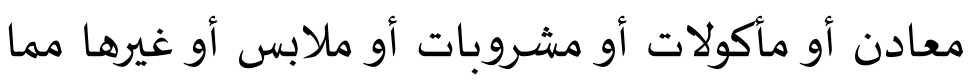

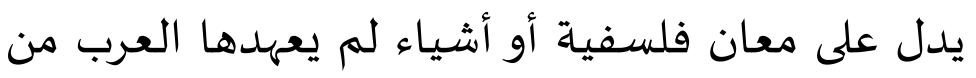

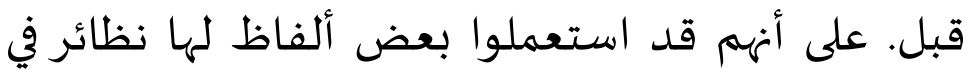
العبية لبعض الأسباب، من ذلك خفتها على اللسـان.

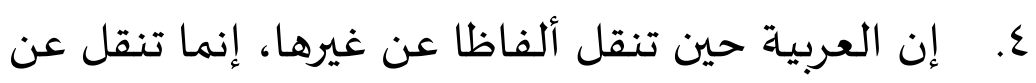

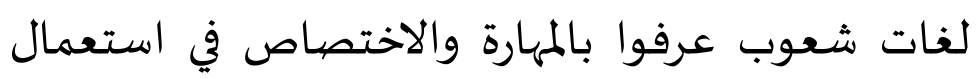

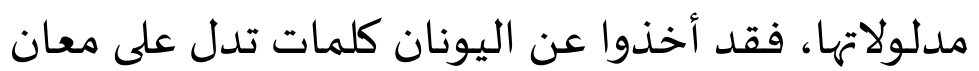

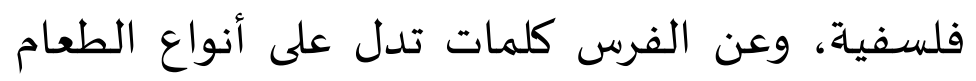
والشراب أو الملابس أو الزهور، وما إليها.

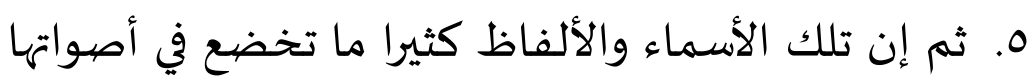
وموازنها الصرفية لما هو متبع من العربية.

ففي العصر الجاهلي - أي قبل مجيء الإسلام - أخذ العرب من الفارسية ألفاظا مثل: المهرجان، والنرجس، النهاء

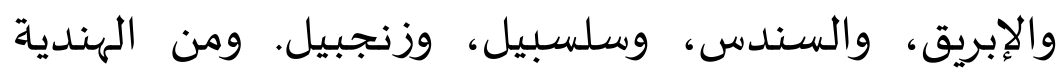
أخذوا: الفلفل، والقرنفل، والشطرنج. ومن اليونانية أخذوا: القسرطاس، والفردوس، والقنطار. ومن السريانية أخذوا: 
الكنيسة، والكهنوت، و الناقوس، والطور. ومن العبرانية

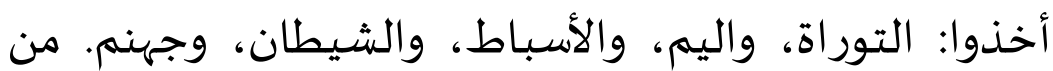

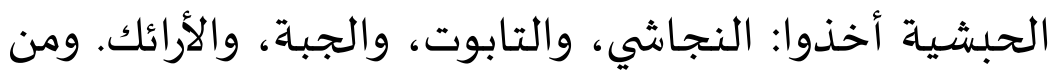

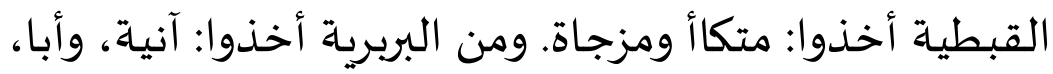
والقنطار.

وحتي في العصر الحديث حينها تعايشت العربية مع

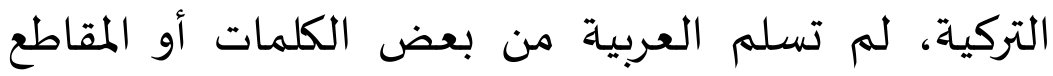

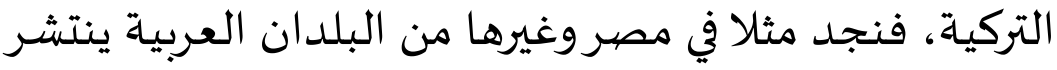

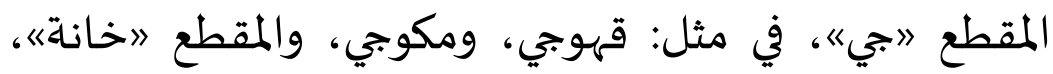
فنرى: كتبخانة، ودواءخانة، وأجزخانة.

هكذا، أثرت اللغة العربية في كثير من اللغات وفي الوقت نفساه تأثرت منها واستمر التفاعل بينهما مدة لا نزال

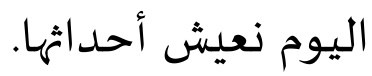

هـ وسائل النمو اللغوي التي تمتلكها اللغة العربية. تمتلك اللغة العربية قدرات عظمة وإمكانات متميزه تمكنها من استيعاب العلوم الحديثة والتقانيات المعاصرة. وفي 
سبيل إنتاج المصطلحات والألفاظ الجديدة فإنها تتخذ وسائل عدة بذكاء القائمين عليها 'r، وفي مقدمة تلك الوسائل:

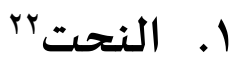

النحت هو انتزاع كلمة من كلمتين أو أكثر على سبيل الاختصار، على ان يكون هناك توافق في اللفظ والمعنى بين

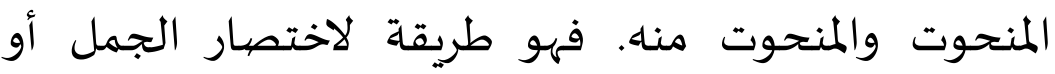
العبارات في كلمة واحدة، ولجأ إليه العرب قديما تعبيرا عن فئن

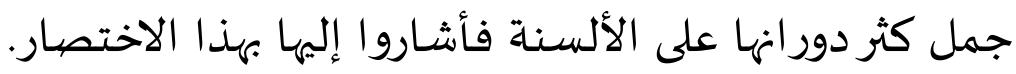
ويجري نحت الكلمات الجديدة بتركيبيها من الحرفين

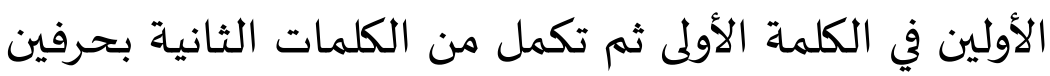
أو ثلاثة، وقد تكون التكملة أكثر من ثلاثة. ولعل الأمثلة الآتية

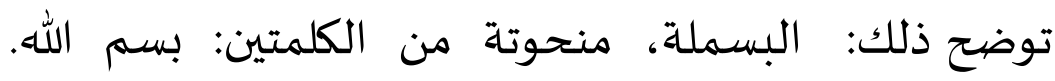

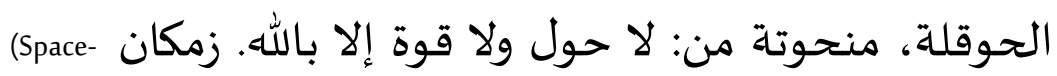
time)

r ب في مقابلة صحفية قامت بها مجلة الأمة القطرية في عددها عr مع المستشرق

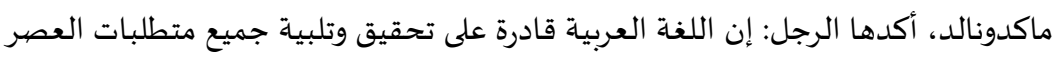

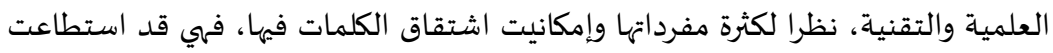
أن تلبي حاجة كل العصيورفيما كان من مختراعات اليوم فلن يعجزها ذلك.

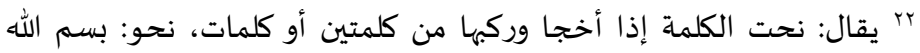

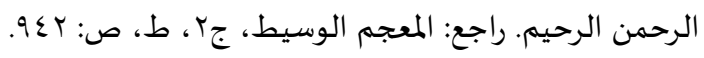


(Electromagnetic) ، منحوتة من كلمتين، هما:كهر بائي، ومغنطيسي مافوسبجي (Ultraviolet)، منحونة من كلمتين، هما: مافوق، والبنفسبجي.

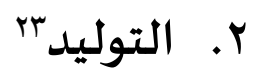

يؤكد الباحثون - منهم: أ. د. عبد الصبيور شاهين عَ- أن التوليد كان خير وسيلة إلى الإثراء اللغوي والمراد باء: استعمال الناطقين للغة لفظا لم تكن مما روي عن العرب في القرنين الأولين أو القرون الثلاثة الأولى التي توصف بأنها عصر الرواية،، وهو العصر الذي اعتمد العلماء فيه كل ما روى من اللغة عن العرب في بواديهم وحواضرهم، و يطلق على عملية استخراج اللفظ الجـديد، أو استعمال اللفظ القديم في المعنى الجـديد، سواء أكان اللفظ عربي الأصيل أم كان معربا. ولقد تتبع أ. د. عبد الصبور شاهين - صاحب كتاب ״العربية لغة العلوم والتقنيةه الذي صدرت الطبعة الأولى في الممكلة العربية السعودية سنة سر919، ثم أعيد طبعة في

r"r يقال: ولد الكلام والحديث أي استحدثه، راجع: المعجم الوسيط، ج: r ، ط:

$$
\text { . } 1.91: \text { r } 19
$$
عr هو أستاذ الدراسات اللغوية بكلية دار العلوم، جامعة القاهرة، بمصر.

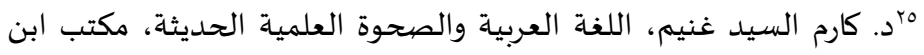

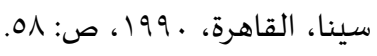

Jurnal Izdihār : Journal of Arabic Language Teaching, Linguistics, and Literature 
القاهرة سنة 1917 - الألفاظ التي وصفت بالتوليد فوجدها لا تخرج عن أشكال الخمسـة، بال:

الشكل الأول: التوليد الذي يأتي على أسـاس قاعدة يطردها أصحاب اللغة لضرورة تعبيرية، كتلك القاعدة التي وضعها المجمع اللغوي لصوغ المصيدر الصنايي بإضيافة اللاحقة "يّية" - ياء مشـددة وتاء مربوطة - إلى الاسمى عند ترجماة الكلمات المنهية باللاحقة 》ism في الإنجيليزية. وقد كانت هذه القاعدة وسيلة إلى خلق كلمات كثيرة، مثل: الرومانسيةة، والإيدولوجية، ، والعقائدية، والكلاسكية، والاشتراكية، والواقعية، والتعددية، والإقطاعية، والأنانية. وهذه الألفاظ منها ما هو قديم نسبيا، فهو "مولد《، ومنها ماهو حديث، فهو

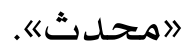

الشكل الثاني: نوع من التوليد الإبداعي الذي يأتي في

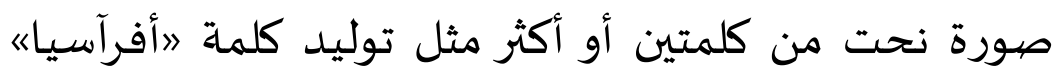
للدلالة على قارتي أفريقيا وآسيا، وتوليد كلمة 》البيزة《 من كلمتي البازي والصقر، تدل على العلم الذي يبحث في أحوال الجوارح وقوتها على الصيد.

الشكل الثالث: توليد يقوم على استغلال جرس الصيوت ومحاكاته، كتسمية الهمزة 》بالبسّةـه، وتوليد كلمة

$$
\text { M كارم سيد غنيم، المرجع السابق، ص: 01 - . 7، بتصرف. }
$$


״اختباررنه في الطب للدلالة على اختبار التوصيل العظمى بشوكة رنانة، وهو مولد من رن رنينا.

الشكل الرابع: التوليد الذي يتم على أساس التوسع في رئي

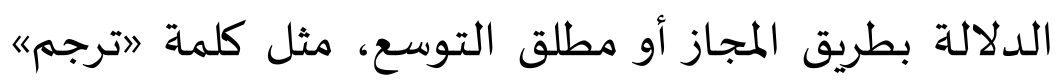

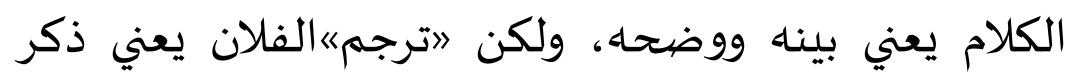

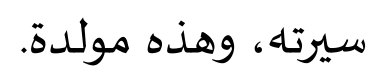

الشكل الخامس: التوليد الاشتقاقي، مثل ذلك: جنس، وهولده

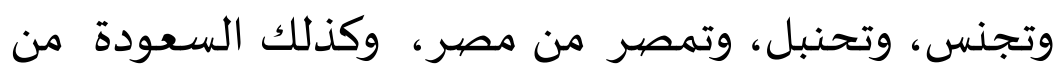
السعودية، والبحرنة من البحرين، والأسلمة من ونس الإسلام.

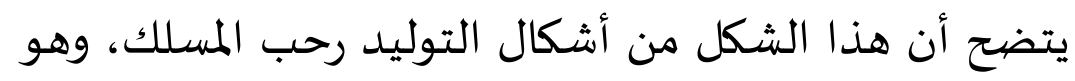
صالح لوضع كلمات جديدة حين تقتضي الضرورة.

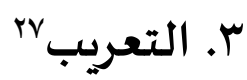

2، التعريب هو صبغ الكلمة يصغة عربية عند نقلها بلفظها الأجنبي إلى اللغة

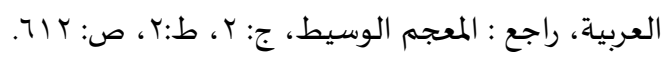

Jurnal Izdihār : Journal of Arabic Language Teaching, Linguistics, and Literature 
يقصد باء تحويل كلمة أعجمية إلى عربية^^، وله أربع

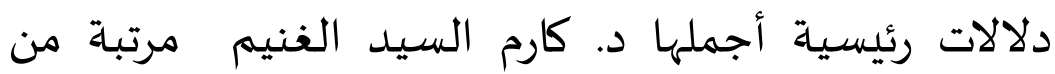

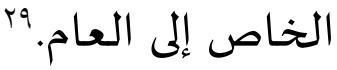

أولا : التعريب هو نقل الكلمة الأجنيبة ومعناها إلى اللغة العربية كما هي دون تغيير فيها، أو مع إجراء تغييروتعديل

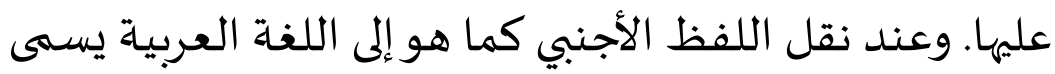

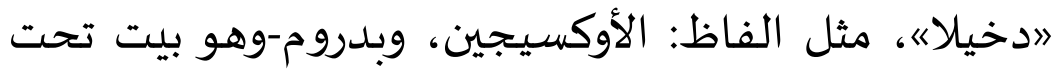

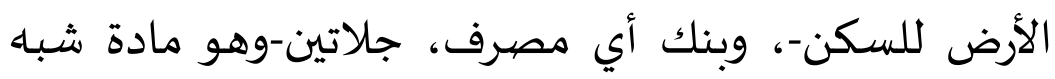

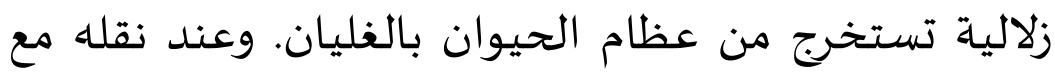
تغييره يسمى 》معرباه، مثل ألفاظ: التليفون، والتلغراف.

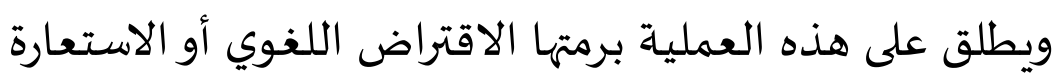

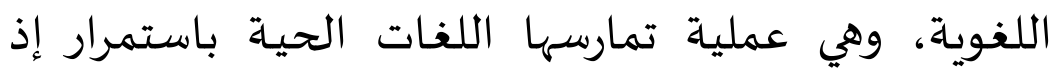

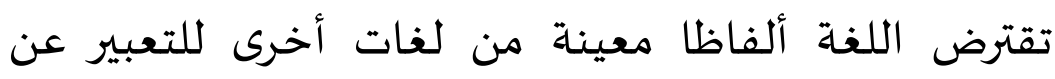

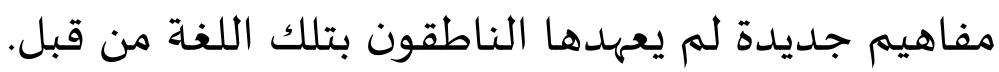

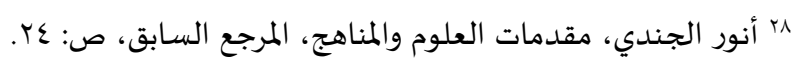

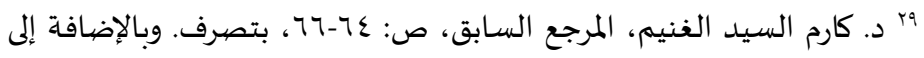

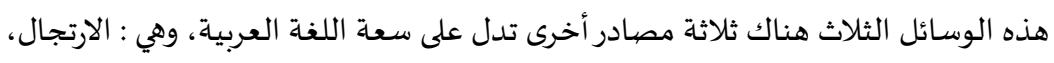

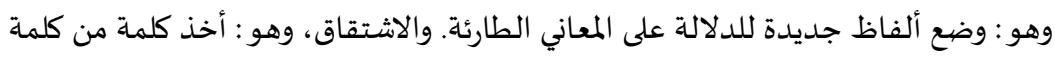

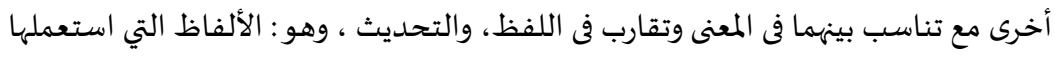

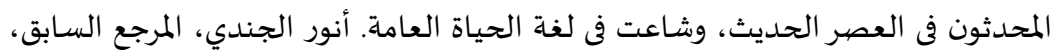


ثانيا : التعريب هو نقل معنى نص من لغة أجنبية إلى اللغة العربية، وقد يتألف النص من فقرة أو كتاب بكامله. والتعريب بهذا المعنى مرادف للفظ هالترجمةشها.

ثالثا : التعريب هو استخدام اللغة العربية لغة للإدارة

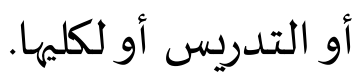

رابعا : التعريب هو اتخاذ قطر بأكمله اللغة العربية لغة حضارية له أي تصبح لغة التخاطب والكتابة السائدة

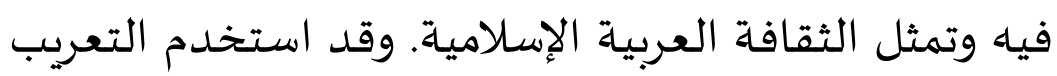
ههذا المعنى فى صدر الإسلام إبان الفتوحات الإسلامية وبعدها.

و- بعض الأسـاسيات في تعليم اللغة العربية للناطقين بغيرها.

بناءً على ماسبق، وانطلاقا من حرصنا على نشر هذه اللغة العظيمة بين شعب هذا الوطن العزيز يلزمنا في النهاية أن نشير إلى بعض الأساسيات المطلوبة عند القيام بتعليمها،

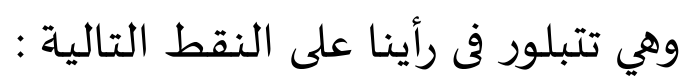
أ. أن يكون التعليم مبنيا على الجمع بين نظريتي الوحدة 
(Poly systemic Approach) • (All in one System)

$$
\text { ويتم ذلك على ما يلي: }
$$

ا. ألا نعتبر أي فرع من فروع اللغة العربية قسما يلئ

$$
\text { قائما بذاتاه منفصلا عن غيره. }
$$

r. أن ننظر التقسيم على أنه تقسيم صناعي يراد

باه تيسير العملية التعليمية وزيادة العناية بلون

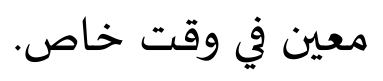

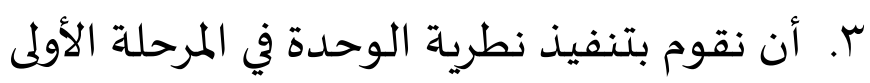

والمرحلة المتوسطة، ونظرية الفروع في المرحلة

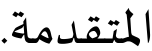

ب. أن يتوافرعند تعليم هذه اللغة المعلم الجيد باعتباره

العمود الفقري والعامل الرئيسي في نجاح العملية

التعليمية حيث أنه يمتلك قوة التأثير في العناصر

rيراد ها: أن تعلم العربية كوحدة مترابطة متماسكة لا تتجزأ بعض فرومحها

بن بعض، والتعليم بثه هـ الطريقة عتن كن العناية بكسب المهارات اللغوية الأبع وبإلقاء كناصرها وفروعها متحدة لا تتجزأ

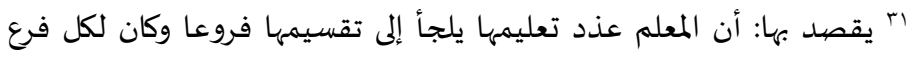

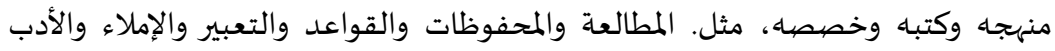

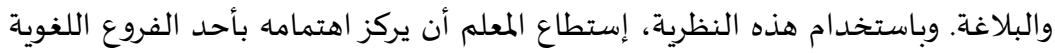
في وقت خاص، إلا أن فيها، كما هو المعروف، تمزيق اللغة يفسد جو هرها ويخرجها من ون

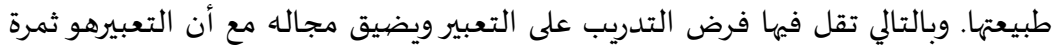
الدراسات اللغوية جميعها. 
الأخرى اللازمة عند التعليم، والحكمة تقول: الطريقة أهم من المادة. والمدرس أهم من الطريقة.

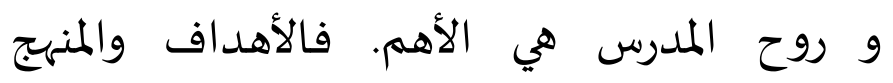
والوسائل والطريقة والتقويم جميعها تظل أدوات صماء بدون معلم جيد يتمتع بالسمات الشخصياة

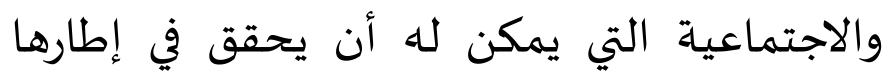

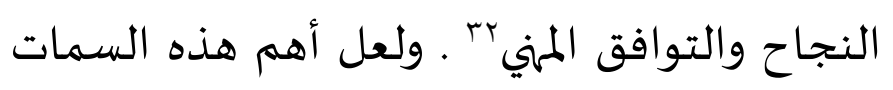
هي: 1. التدين، فهو مصدر كل نجاح ومعيار الإخلاص والصدق في تحقيق الأهداف المنشودة. r. الثقة بالنفس، وهي إدراك المعلم لذاته وإيمانه بمهنة التدريس وحماساه وحباه للعمل فيها.

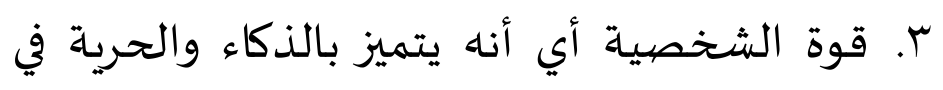

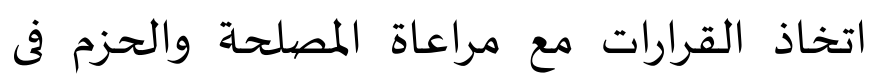
المعاملة. ع. الإلمام بالمادة التعليمية والدراسـات النظرية التي تساعده فى رفع مستوي الدارسين.

\footnotetext{
rrللتفصيل راجع: د.دحية مسقان، نحو استراتيجية تعليم اللغة العبية

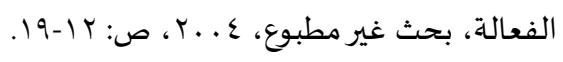

Jurnal Izdihār : Journal of Arabic Language Teaching, Linguistics, and Literature 
0. اجتماعي الطبع، أي يتميز بالسلوك الاجتماعي مع تلاميذه ويكون علاقات طيبة معهم.

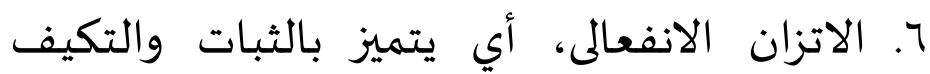

$$
\text { العاطفي في أقواله وأفعاله. }
$$

V الفاعلية الشخصية، أي الايجابية والقدرة على الفواهله التفاعل بين العناصر الأخرى في العملية التعليمية.

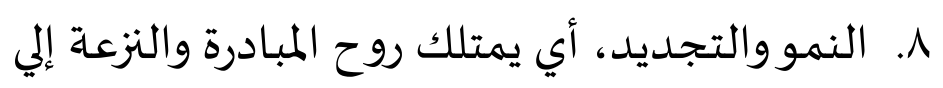

$$
\text { التجديد والقيام بالتجريبة. }
$$

9. الموضوعياة والتواضع، أي عدم التمييز والتعصب بالتجربه

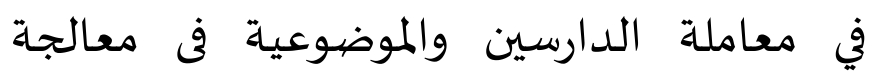

$$
\text { الدروس والتواضع دون إهدار لكرامته. }
$$

ج. أن يستخدم المعلم عند القيام بتعليمها الطريقة

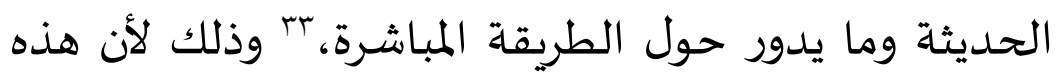

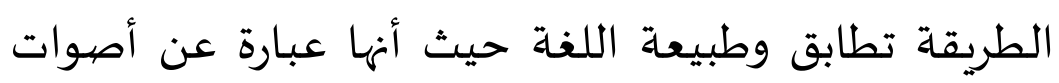

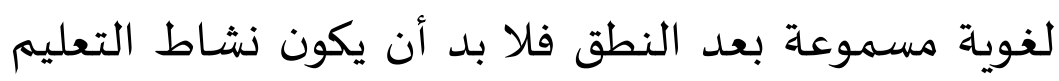

"rآوهي الطر يقة التي لا يذكر منها المعلم معنى الشيء بلغة الدراس أثناء التدريس،

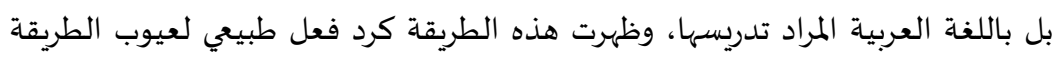

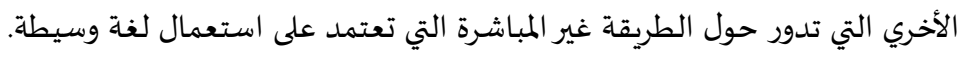


اللغوي مرتبا لكسب مهارات الاستماع والمحادثة ثم القراءة والكتابة. وقد أشار بعض اللغويين إلى هذه الحقيقة بقولهم:

Nothing should be spoken before it has been heard... Nothing should be read before it has been spoken..

وتعتمد هذه الطريقة على وضع الدارس داخل "حمام

اللغة" بالإكثار من التمرينات والتدريبات للسماع والمحاكاة و الاتصال حتى يستطيع أن ينطق باللغة العربية أوتوماتيكيا.

ومن الأهمية بمكان، ونحن نتحدث عن واقع تعليم

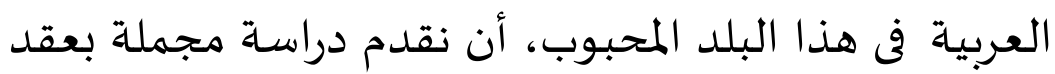
المقارنة التي تدور حول أولوية تقديم المهارات اللغوية وعناصر المربه اللغة عند التعليم بين المدرسة الحديثة وبين المدرسة المهاه

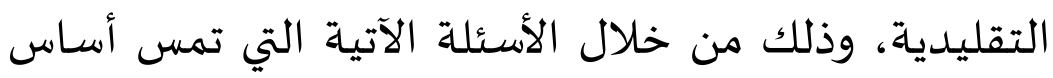

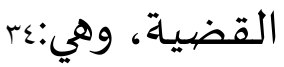

أية المهارة تعلم أولا؟ الكتابة والقراءة أم الاستماع و

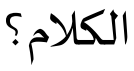

هل يبدأ التعليم بتدريبات الأذن المنتظمة وتدريبات

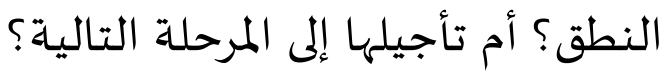

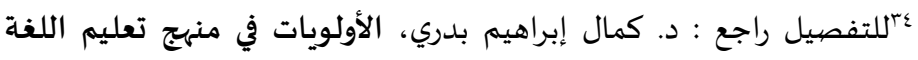

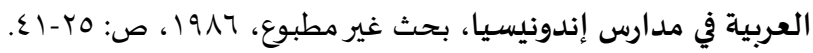

Jurnal Izdihār : Journal of Arabic Language Teaching, Linguistics, and Literature 
أين الأحسن تعلم الكلمة أولا أم الجملة؟

هل تنطق اللغة في بطء ووضوح منذ المرحلة الأولى أو

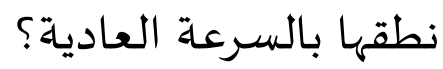

هل الاعتماد على التدريبات أم على الترجمة ؟

1. أية المهارة تعلم أولا؟ الكتابة والقراءة أم الاستماع

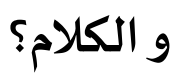

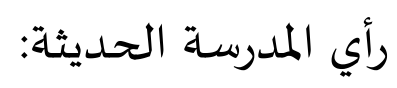

ترى المدرسة الحديثة أن تبدأ بتعليم الاستماع والكلام

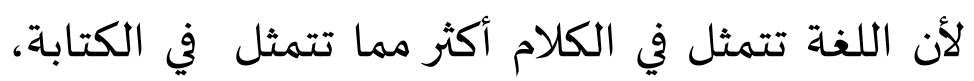

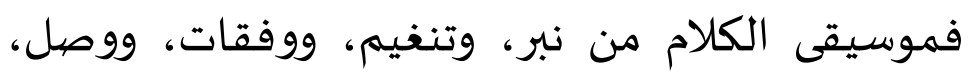

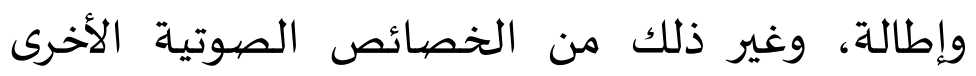

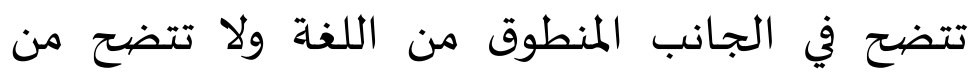

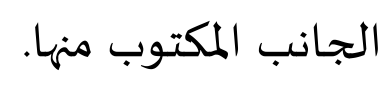

إنّ اكتسـاب مهارة الكتابة والقراءة قبل تعليم أنماط مهاط اللغة شفاهة لا يعد طريقة ميسورة وغير فعالة، والتجارب التربوية أثبتت هذا الإحساس. ويمكن للمربي أن يطبق هذا الأسساس على التعليم حتى التى

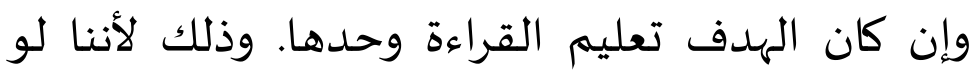


علمنا الطالب أنماط اللغة بالطريقة السمعية الشفهية

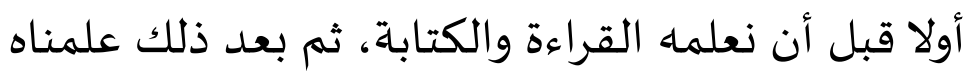
هاتين المهارتين لأمكنه الترقي بمستواه التحصيلي في

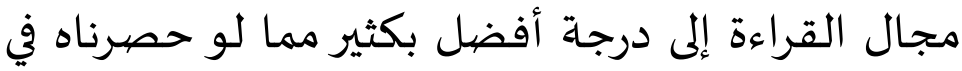
تعلم الرموز الكتابية وحدها، يضاف إلى ذلك أن تعلم النظام الصوتي وحده يساعد كثيرا في مادة الإملاء، ويمكن تأييد وجهة النظر بحوانب "تكتيكية" نورد منها ما يلي : منها : لو أخذنا فئتين من الطلبة إحداها بدأت تعليمها لا

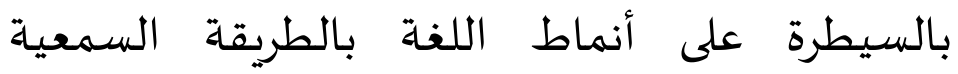
الشفهية، والأخرى بدأت تعلم الرموز الكتابية فإننا

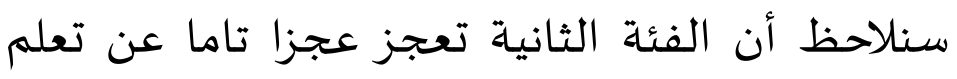
الكلام بأنفسهم. منها : لو نظرنا إلى مدى الاستعداد والرغبة في مواصلة التعلم

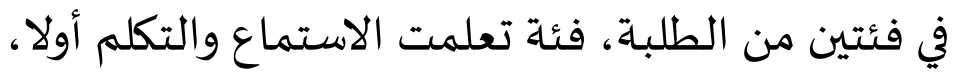
وفئة بدأت تتعلم الكتابة لوجدنا أن الفئة الأولى قد الفئه

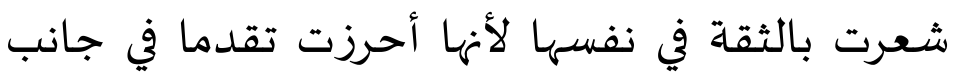
اتصالي هام هو الكلام، بحلاف الفة الثانية التى ستميل باليل إلى الاعتقاد بأن عملية الكلام أمرشاق. 


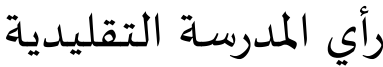

ترى المدرسة التقليدية البدء بالكتابة قبل الاستماع

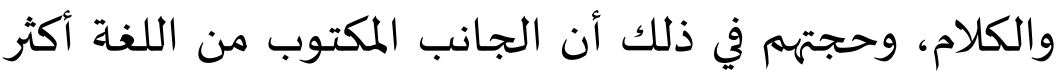
ثباتا من الحا نب المنطوق، فالجانب المكتوب لا يتغير بتغير الأقاليم، بخلاف اللغة المنطوقة فهي تختلف باختلاف

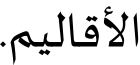

وترى أيضا أن تعلم الكتابة سهل ويتم في وقت قصير، ولهذا يشعر التلميذ الذي تعلم النظام الكتابي للغة الهدف

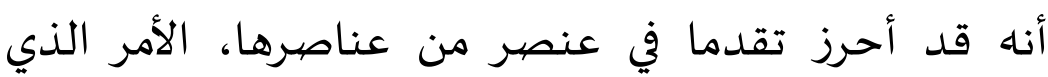
سيحفزه على مزيد من التقدم والثقة.

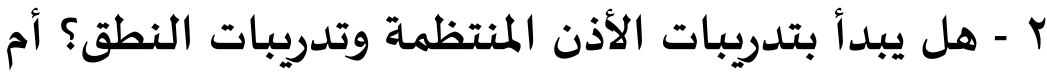
تأجيلها إلى المرحلة التالية؟

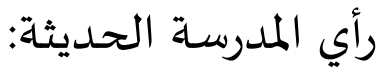

ترى المدرسة الحديثة أن تبدأ برامج تعليم اللغة المدية:

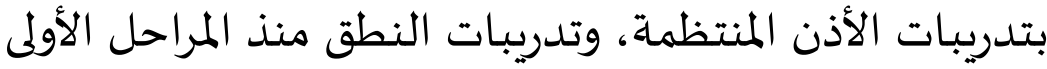
للتعليم، ولا يؤخر ذلك إلى المرحلة التالية خوفا من أن أن يكتسب الطالب عادات النطق الرديئة فيصعب تخلصها منها، وإذا اكتسبها جاء العمل المرتب على ذلك لكنه في النطق أقرب

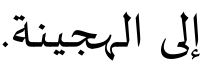

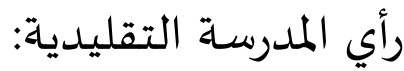


ترى المدرسة التقليدية الابتعاد عن تدريبات الأذن والنطق في المراحل الأولى ظنا منها أن مثل هذه التدربيات

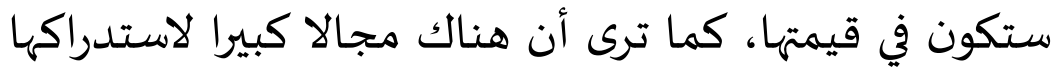

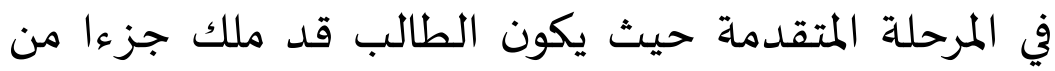

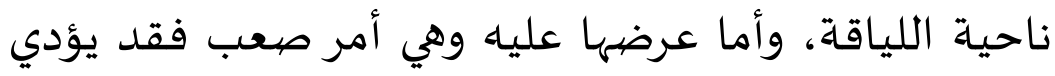

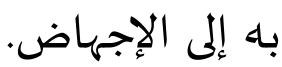

وبالنظر إلى هذين الرأيين من المدرسة الحديثة والمدرسة التقليدية، فالأرجح في تعليم اللغة العربية للدرسين

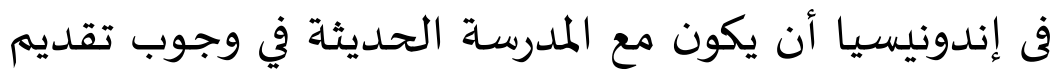
تدريبات الأذن والنطق منذ اليوم الأول للبرامج اللغوية، ويتم تدريبات الأذن بعدة طرق، أسهلها ما يأتي:

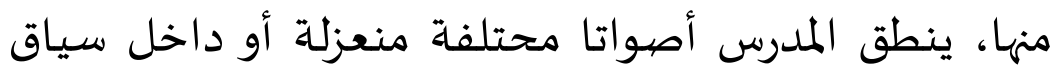

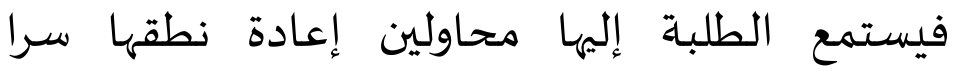

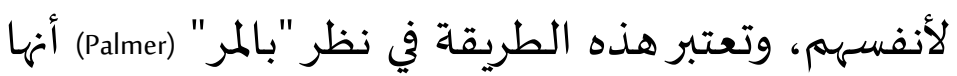

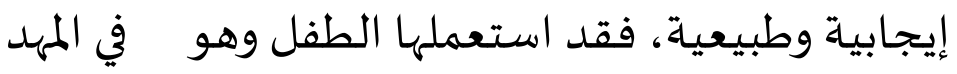
يستمع إلى الأصوات التي يصدرها الناس من حولها

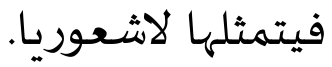
منها، يعطي المعلّم الطلبة بعض الأصعوريا. يعطيهم أصواتا متشابهة ليقوموا بالتفريق بينها. 
وأما تدريبات النطق فتتم وفقا للخطوات التالية: منها، يبدأ المعلّم بتدريب الطلبة على الأصهوات المألوفة

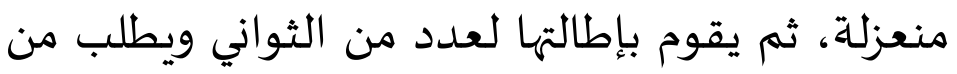

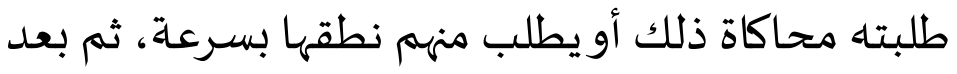
ذلك ينطقونها داخل كلمات جديدة غير مألوفة لديهم. منها: أن يشجع المعلّم الطلبة على استغلال مقدرتهم على داخلى

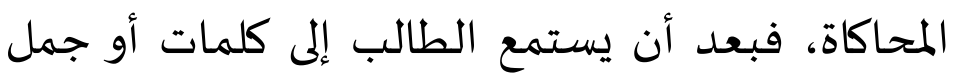

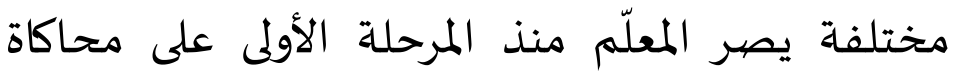

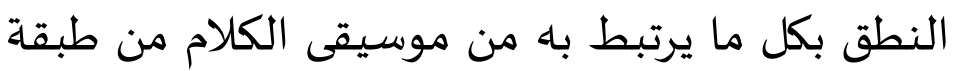
وطول ووقف وغير ذلك من الدقائق الصوتية الأخرى.

r- أين الأحسن تعلم الكلمة أولا أم الجملة؟

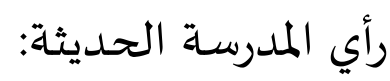

ترى المدرسـة الحديثة أن يبدأ بتحفيظ الجمل وكيفية المدائة تركيبها قبل تحفيظ الكلمات واشتقاقات تصريفها، وبمعنى

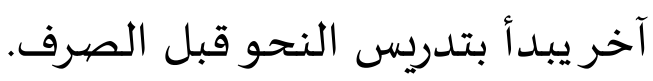

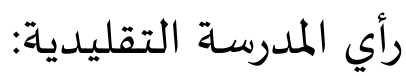
ترى المدرسة التقليدية الابتداء بتحفيظ الكلمات

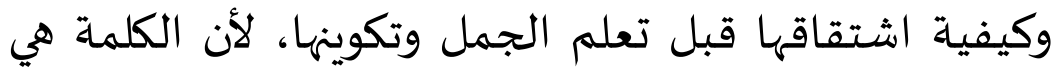
وحدة الكلام الأساسية، هذا من ناحية، ومن ناحية لفية أخرى 
تكون الكلمة أصغر من الجملة، ولذا فإن تعلمها يكون أسهل،

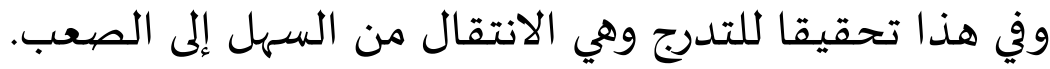

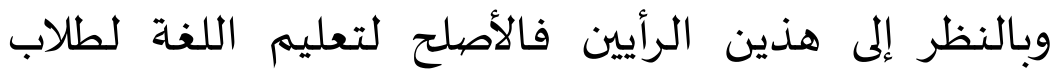

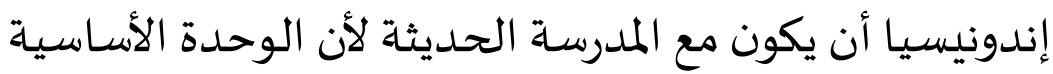

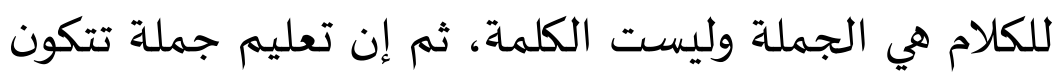
من سبع كلمات معناه تعليم سبع دفعة واحدة، ثم إن الكلمة

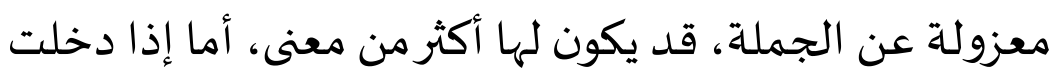

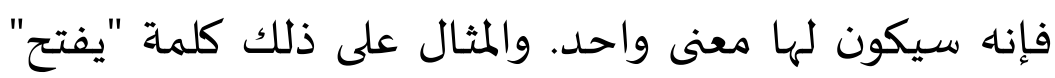
فهي تعني عدة معان، يمكن التمثيل لها بالجمل التالية: يفتح على الباب. يفتح على حسابا في البنك. يفتح الله عليا

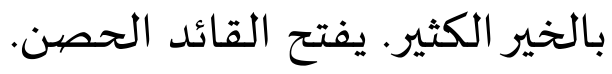

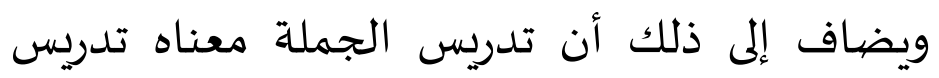
تركيب معين بجانب تدريس أقسام الجملة خبرية أو إنشائية أو قطعية استفهامية أو تقريرية أو تعجبية، مثبتة أو منفية.

ع- هل تنطق اللغة فى بطء ووضوح منذ المرحلة الأولى أو

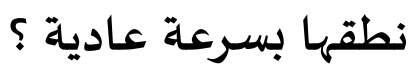

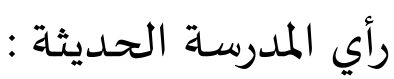


ترى هذه المدرسة وجوب تعلم اللغة كما تستعمل فى الحديث العادي أى بالسرعة العادية التى ينطق بها أبناء اللغة، فإن ذلك يؤدي إلى اكتساب الطلاقة، أما الثانى فهو إحدى مميزات الهجنة، وأما التخاطب (الإلقاء الخطابي) فلا يمثل اللغة الطبيعية بأي حال من الأحوال.

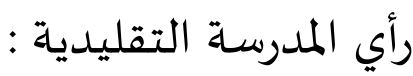
تري هذه المدرسة أن نطق اللغة في بطء ووضوح يستطيع الطالب معرفة تفاصيلها حتى يسمعها ويدرك كلماتها، إذ كيف يفهم الجملة إذا نطقت بالسرعة التي يتكلم

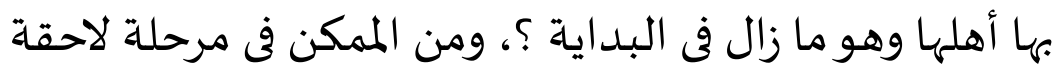
أن يتمرن على النطق السريع.

ه- هل الاعتماد على التدريبات أم على الترجمة ؟

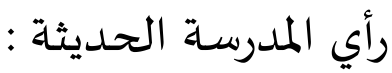
ترى المدرسة الحديثة الاعتماد على التدريبات لأن

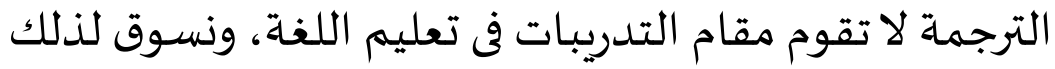

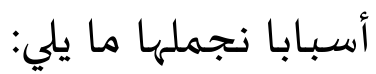

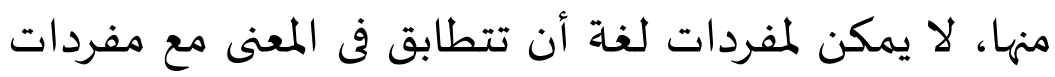

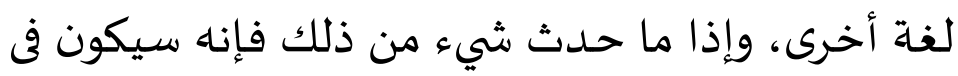

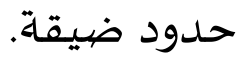


منها، إن الطالب الذي يعتقد أن الكلمات المترجمة تطابق فى

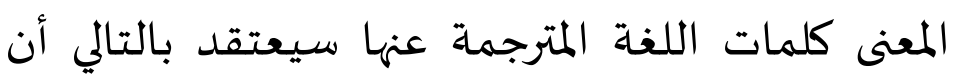
ترجمته تعبر عن نفس المواقف التي تعبر عنها اللغة الأخرى، وهذا يؤدي إلى خطأ جسيم. منها، إن الترجمة الحرفية كلمة فكلمة تؤدي إلى تكوين تراكيب

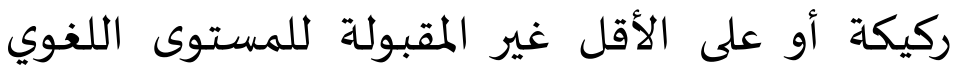

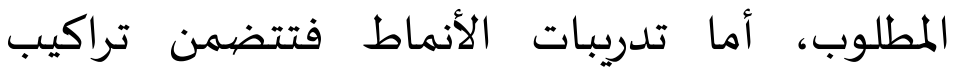

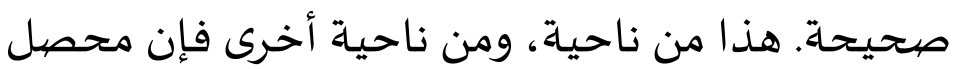

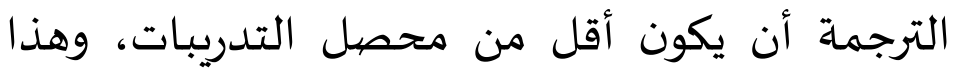

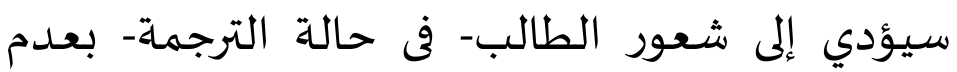
التقدم.

\section{رأي المدرسة التقليدية :}

ترى هذه المدرسـة أن الترجمة أمر ضروري في توضيح المعنى وفى معرفة خصائص اللغة الهدف وفى تمكين الطالب

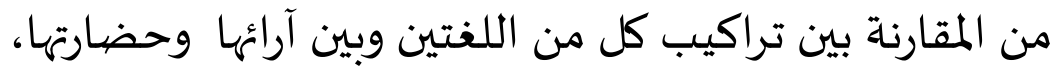

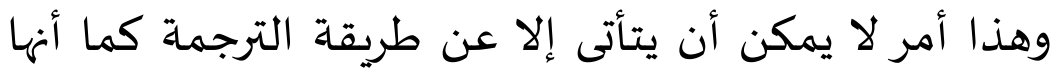
طريقة لقياس مستوى الطلبة. 


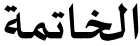

لقد صبدق المفكر الإسلامي الكبير د. محمد إقبال حين

أعلن وقرر "إن سر الحياة هي الحركة" في أنشودته الجميلة:

\begin{abstract}
The motionless bank of river said "In my long existence I have contemplated much to know what I am, but the meaning of my existence has not been revealed to me." Hearing this the fast-moving and tumbling wave replied, "The secret of life and the essence of it is movement; / exist so long as / move, when I cease to move I shall cease to be. ${ }^{35}$
\end{abstract}

إنه ليس مجرد الحركة، وإنما الحركة القائمة على

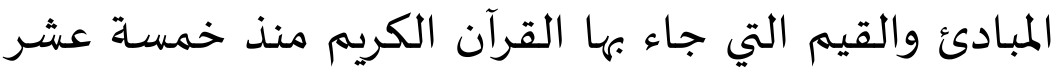
قرنا من الزمان، فإن تلك القيم والمبادئ إذا تم تفعيلها وتحويلها إلى برامج عمل، كما حدث في الماضى، فإنها قادرة بدون شك، على الوفاء بكل المتطلبات ومواكبة كل التطورات فى هذا العصر الذي يحلو لنا تسميتها بعصر العولمة وفى غيره

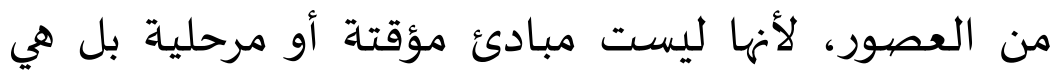
مبادئ أساسية ثابتة تصاحب البشرية في كل مراحل تطورها

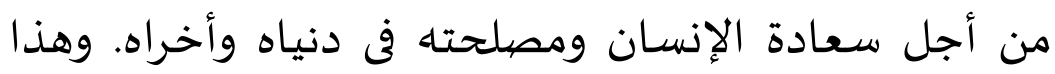

${ }^{35}$ Khalifah Abdul Hakim, Renaissance in Indo-Pakistan, in A History of Moslem Philosophy, ed. M. M. Sharif, vol: Il, 1983, p: 1632. 
يعني أننا مطالبون ببذل المجهود أضعافا مضاعفا لدراسة

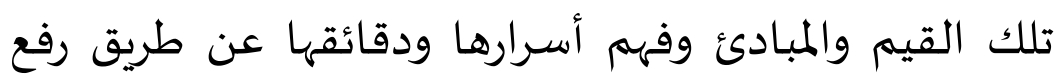

مستوانا وكفاءتنا اللغوية - ونخض بالذكر اللغة العرانة العربية بالإضافة إلى قدراتنا الفكرية والثقافية.

ثم إننا من خلال ما أوردنا في الصفحات السابقة لم

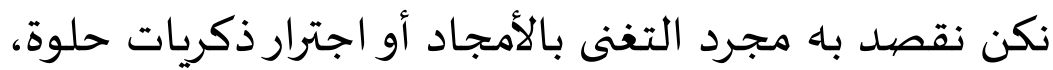

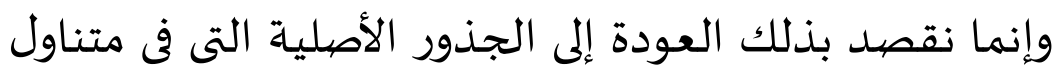
أيدينا لأخذ الدروس والعبر من ماضينا العريق حتى يتسنى لنا مواصلة السير على الدرب ونبنى كما بنوا ونستمر في البناء

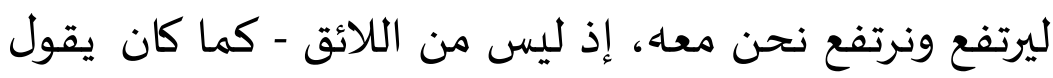

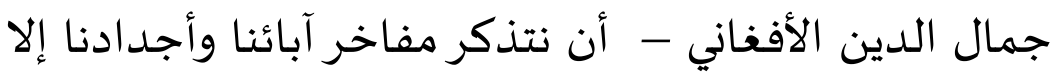

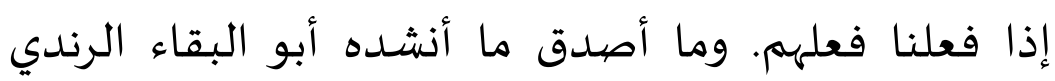
الأندلوسي:

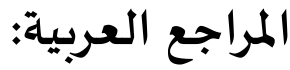

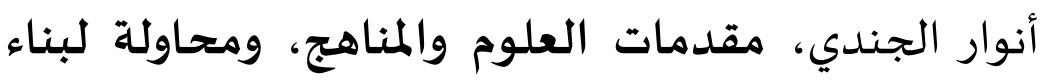
منهج إسلامي متكامل، دار الأنصار، القاهرة، د.ت

دحية مسقان، نحو استراجية تعليم اللغة العربية الفعال،

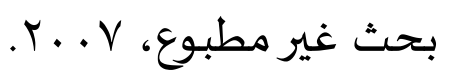

Jurnal Izdihār : Journal of Arabic Language Teaching, Linguistics, and Literature 


\section{دون الاسم، الاتجاهات الحديثة في التعليم اللغة العربية}

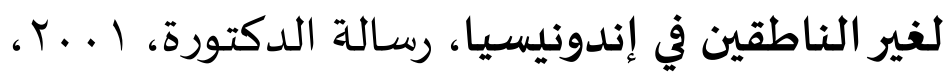

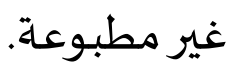

رمضيان عبد التواب، فصيول في فقه العربية، ط: r، مكتبة

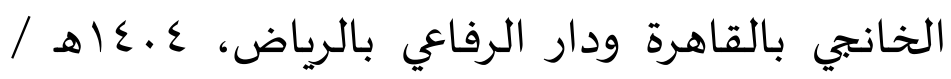
م. سعيد عبد الفتاح عاشور، حضـارة الإسلام، معهد الدراسات

$$
\text { الإسلامية، القاهرة، د.ت }
$$

سيد قطب، في ظالال القرآن، دار الشروق، المجلد السـادس،

$$
\text { د. - n }
$$

سيغريد هونكة، شمس العرب تسطع على الغرب، أثر

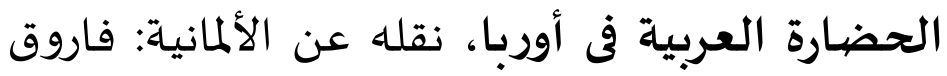

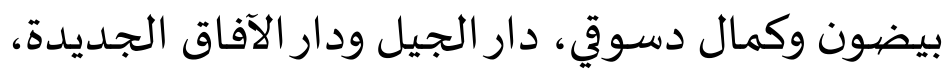

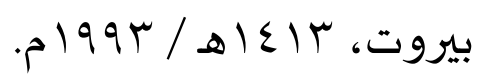

صالح آدم بيلو، الثقافات الأجنبية في العصر العباس (Yr

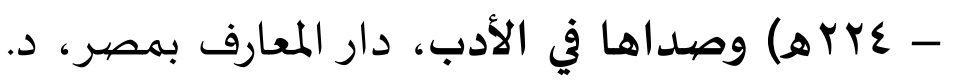

$$
\text { ت }
$$


عبد الغفار حامد هلال، العربية خصائصها وسسماتها، ط:

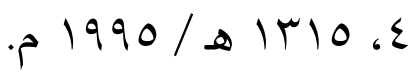

على عبد الواحد وافي، علم اللغة، مكتبة نهضية مصر،

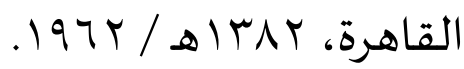

كارم السيد غنيم، اللغة العربية والصحوة العلمية الحديثة، مكتب ابن سينا، القاهرة، . 199.

كمال إبراهيم بدري، الأولويات في منهج تعليم اللغة العربية في مدارس إندونيسيا، بحث غير مطبوع، 1917.

محمد حمدي زقزوق، مقدمة الفلسفة الإسلامية، معهد

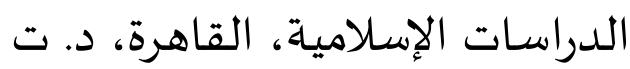

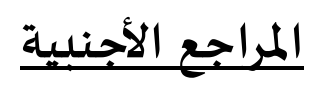

Edward, Al-Beruni's Book of India, edited with note and indices by: C. Sachau

Arabic Language, Encyclopedia Britannica, vol. 2, 1971

Khalifah Abdul Hakim, Renaissance in Indo-Pakistan, in A History of Moslem Philosophy, ed. M. M.Sharif, vol: II, 1983

Sabah Ghazzawi, The Arabic Language, Washington DC, Center for Contemporary Arab Studies, 1992

Jurnal Izdihār : Journal of Arabic Language Teaching, Linguistics, and Literature 
TJ. De Boer, The History of Philosophy in Islam, translated into English by Edward R. Jones, Cosmo Publication, New Delhi, 1983

Ahmad Fuad Effendy, Metodologi Pengajaran Bahasa Arab, Cet. 3, Misykat, Malang, 2005. 